\title{
DIREITO COMPARADO E TRADUÇÃO JURÍDICA: ESTUDO DE CASO
}

\section{Márcia Atalla Pietroluongo}

A função e a importância do Direito Comparado para a tradução jurídica têm sido enfaticamente ressaltadas pelos mais diversos teóricos da tradução do Direito (Gemar, Legrand, Glanaert, Sacco, Dullion, dentre inúmeros outros). A perspectiva comparatista coloca os juristas diante da necessidade de exposição e apresentação do Direito estrangeiro ao Direito nacional, e vice-versa, confrontando-os à evidência das não-equivalências, à ausência de superposição conceitual ou institucional de um sistema jurídico a outro. A questão da traduzibilidade é, assim, colocada sistematicamente em causa.

É de fundamental interesse analisar as funções e os aportes que o Direito Comparado pode trazer ao campo da Tradução Jurídica, examinando como resolvem (ou não) os impasses comparativos e tradutórios com que são confrontados, posto que os juristas comparatistas, por seu ofício, se obrigam a traduzir, acabando por se constituir em tradutores não profissionais. Embora não se trate de tradução stricto sensu, não havendo um "original" a partir do qual o comparatista traduza, mas sim da tradução enquanto operação de reformulação mental, e enquanto comparação de sistemas jurídicos, busca-se aqui investigar, a partir do estudo de um caso emblemático, o modo como os institutos e as instituições jurídicas são apresentados de uma língua-cultura para outra, operando, por assim dizer, um exercício de tradução no interior do Direito Comparado.

Como lembra Sylvie Montjean-Decaudin (2012, p. 295), a simples leitura de outro Direito, ainda que na mesma língua (um jurista francês, por exemplo, lendo um texto de Direito belga), já pressupõe uma comparação. Esta "é inerente à tomada de conhecimento do Direito do outro, quaisquer que sejam os Direitos confrontados. A partir do momento em que o Direito Comparado consiste em fazer um paralelo entre dois Direitos, ele contribui para o processo tradutório dos textos jurídicos" (p. 296) ${ }^{1}$.

\footnotetext{
* O presente artigo resulta da pesquisa realizada no âmbito do Pós-Doutorado por mim realizado no Programa de Pós-Graduação em Estudos da Linguagem da PUC-RIO, no período de 01 de agosto de 2013 a 31 de julho de 2014, sob a supervisão da Professora Helena Franco Martins.

Uma versão muito reduzida e ainda preliminar deste artigo foi apresentada na XI Congresso Internacional da ABRAPT e V Congresso Internacional de Tradutores em setembro de 2013 na Universidade Federal de Santa Catarina.
} 
Etienne Picard (1999, p. 158) salienta que

o comparatista é bem mais do que um simples tradutor de palavras ou frases jurídicas escritas originalmente, com muita frequência, em uma língua estrangeira: ele é realmente um intérprete de conceitos jurídicos, uma espécie de interface que os faz passar de uma língua para outra, buscando vias de passagem que permitam que uns e outros se comuniquem e se compreendam.

Dentre as diversas categorias de juristas, os comparatistas fazem parte daquela que se pode considerar a mais erudita, mais capaz de compreender as sutilezas dos Direitos nacional e estrangeiro. Investigando o peso da cultura na compreensão do Direito, Jean-Claude Gémar (2002, p. 168) afirma:

Ora, o leitor nem sempre é capaz de apreender, além de seu alcance jurídico, a carga cultural de um termo ou expressão da linguagem do direito [...]. Distinguirei quanto a isso, a exemplo de inúmeros juristas, quatro grandes categorias de leitores, do mais inculto ao mais erudito: 1) o leitor leigo mais ou menos letrado; 2) o leitor letrado ("o honnête homme ou femme" do século XVIII); 3) o jurista prático (os profissionais da lei); 4) o erudito (teórico, comparatista, entre outros). Conforme o texto jurídico seja lido por um ou por outro de tal categoria, seu teor jurídico será mais ou menos bem apreendido, mas o fundamento cultural (ou sociocultural), salvo exceção, escapará à quase totalidade dos leitores da primeira categoria ou em parte ao leitor da segunda categoria, e até mesmo da terceira.

Com toda evidência, o leitor leigo de um texto (jurídico) redigido numa língua estrangeira experimentará uma dificuldade ainda maior, ao passo que o comparatista, mais bem instruído sobre as diferenças que comporta o Direito estrangeiro em relação ao seu, medirá melhor do que os outros seu peso e alcance semânticos.

Diante do exposto, e a título de ilustração relevante, tomaremos como base de análise qualitativa o Curso de Direito Civil Comparado (Doutorado): 1949-1950 (pg 25-182) do eminente René David, do livro Le droit brésilien: hier, aujourd'hui et demain (2005), organizado por Arnoldo Wald e Camille Jauffret-Spinosi, e publicado pela Société de Législation Comparée.

Tomo como base aqui a proposta de recategorização dos procedimentos técnicos da tradução feita por Heloisa Barbosa (1900) a partir do estudo de Vinay e Darbelnet, VázquezAyora, Newmark, dentre outros. Os procedimentos técnicos de tradução mais frequentes observados concentram-se em três grandes operações: as literalizações (tradução palavra por

\footnotetext{
${ }^{1}$ Todas as traduções dos excertos citados de obras francesas são de minha autoria, salvo a obra traduzida em português que consta nas referências bibliográficas.
} 
palavra / tradução literal / decalque); as transferências (estrangeirismos / estrangeirismos com explicação do significado); e as equivalências.

\section{Procedimentos de LITERALIZAÇÃO:}

\section{a) Tradução palavra por palavra}

- Les professeurs sont choisis, au concours, pour la chaire qu'ils doivent occuper. La carrière normale est d'être professeur adjoint avant de devenir professeur titulaire, dans une chaire ou dans une autre. (p. 157)

○ «N'est-il pas évident, écrit Ph. Azevedo, qu'on méconnaîtrait la nature du sol, dans le municipe de Nova-Iguaçu, en plantant des citronniers dans une parcelle enclavée au milieu d'une immense plantation d'orangers ?» (p. 122)

\section{b) Tradução palavra por palavra + explicação}

○ L'opinion qui est émise est qu'il y a lieu de rédiger un Code proprement dit, mais qu'il faut auparavant préparer ce travail par une œuvre de « consolidation », c'est-à-dire en accomplissant une œuvre qui mettra de la clarté dans le désordre actuel et qui fera connaître, de façon claire, quelles sont les solutions actuelles du droit brésilien. (p. 60)

- Tandis que la lettre de change, conforme à la loi de 1908, existe au Brésil dans les opérations du commerce international et dans la pratique des crédits bancaires, c'est un autre titre qui joue son rôle, dans le commerce intérieur, en tant qu'instrument de

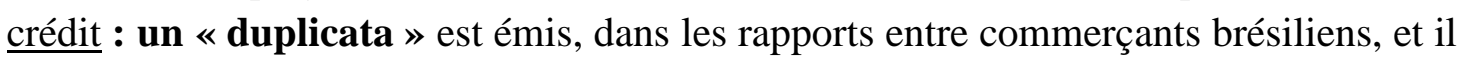
est accepté dans toute vente commerciale à crédit de marchandises. (p. 180)

- (...) la forte personnalité d'un gouverneur (le gouverneur est le chef du gouvernement de chaque État, élu par les citoyens de l'État au suffrage universel et direct) est à coup sûr susceptible d'imprimer à la politique d'un État une marque particulière (...) (p. 46)

\section{c) Tradução literal + ESTRANGEIRISMO}

Fundamentada em Aubert (1987, p. 15), Barbosa considera a tradução literal como "aquela em que se mantém uma fidelidade semântica estrita, adequando porém a morfossintaxe às normas gramaticais da LT (língua de tradução)”. 
○ [...] c'est enfin le mouvement anti-esclavagiste, qui aboutit, en 1888, à la « loi d'or » (lei aurea), abolissant l'esclavage au Brésil. (p. 40)

- Le plus ancien des Codes n'est pas, comme en France, le Code civil, mais le Code de Commerce (Código Comercial) qui date de 1850. (p. 97) (Tradução literal + estrangeirismo)

- La caractéristique du droit brésilien, disait Clóvis Bevilaqua, c'est son caractère « affectueux » (afetividade). (p. 166-167) (Tradução literal + estrangeirismo)

\section{d) Decalque}

Fundamentada em Newmark (1981, 1988), Barbosa afirma que o decalque consiste em traduzir literalmente sintagmas ou tipos frasais da língua original (LO) no texto da língua da tradução (TLT), como aquele empregado na tradução de nomes de instituições.

○ Le Tribunal Suprême Fédéral, qui est établi à Rio de Janeiro, est composé de onze juges, lesquels portent le nom de «ministres ». (p. 128) (Decalque + Explicação + Tradução palavra por palavra)

\section{Procedimentos de TRANSFERÊNCIA.}

A transferência consiste em importar material textual da língua original para o texto da língua da tradução. Ela pode assumir as seguintes formas: 1) estrangeirismo; 2) estrangeirismo + uma explicação de seu significado, que pode vir em: a) nota de rodapé ou b) diluição do texto.

\section{a) Estrangeirismo}

O estrangeirismo consiste na transcrição de vocábulos ou expressões que se mantêm em língua estrangeira no texto traduzido. Vários teóricos e tradutores chamam-no de "empréstimo".

○ La législation propre au Brésil émanant de Lisbonne peut revêtir en la forme les aspects les plus variés : Alvarás, Cartas Régias, Regimentos, Forais, Instruções. [...] Elle organise l'administration de celle-ci, créant les organes administratifs ou judiciaires nécessaires à cet effet et leur prescrivant certaines règles d'action (cf. notamment les Cartas de doação et les forais des capitaineries héréditaires à l'origine, puis la carta-régia de 1589 par laquelle le roi délègue une part de son autorité au 
gouverneur-général de Bahia, et les Regimentos donnés aux différents ordres de fonctionnaires). (p. 51)

- Il suffit d'avoir vu les masures sordides dans lesquelles s'entasse une importante partie de la population, favelas de Rio, mocambos de Recife, pour comprendre que dans un pays où existe un tel gouffre entre les classes sociales, le même droit ne peut pas convenir à la fois aux uns et aux autres ; [...] (p. 168)

\section{b) Estrangeirismo + Explicação (ou vice e versa)}

- Le Brésil n'est développé que sur une très faible partie de son territoire : villes semées le long de la côte avec leur hinterland. États de São Paulo et États du Sud, une partie de l'État de Minas Gerais. Tout le reste constitue ce que l'on appelle le sertão, région de très faible densité, souvent encore mal connue, parfois même inexplorée où l'on vit surtout de l'élevage, sans rapports avec le monde extérieur, assez indifférent à la politique de Rio et à la politique internationale. (p. 29)

○ Les senhores de engenho, propriétaires de plantations sucrières dans le Nord-Est, jouissaient d'une autorité en fait illimitée et non contrôlée dans leurs domaines, qui constituaient autant d'unités pratiquement autonomes. (p. 56)

- Il n'existe pas de juridiction administrative au Brésil, sauf en matière d'impôts où fonctionnent des tribunaux spéciaux, (Varas da Fazenda) en certaines localités ; [...] (p. 127)

Embora a nota de rodapé seja um recurso muito recorrente encontrado nas obras de Direito Comparado, este procedimento no curso de David, em particular, publicado nesta edição brasileira, foi reservado à atualização dos dados feita por Arnold Wald, posto que o curso data de 1949-1950 e o Direito brasileiro sofreu inúmeras e significativas transformações desde então.

Os estrangeirismos com explicações diluídas no texto são igualmente um procedimento maciço e constante observado não apenas no caso estudado, mas em inúmeras obras de Direito Comparado. É preciso salientar ainda que essa necessidade de explicitação, seja através de notas de rodapé, seja através de explicações no interior do próprio texto, encontra-se associada a todos os outros procedimentos tradutórios, e não apenas àquele do estrangeirismo. 
A título de exemplo, segue-se uma nota de rodapé de atualização de Wald, onde se encontram exemplos de decalque, estrangeirismo e explicação diluída no próprio texto:

- (Nota 33) Depuis 1988, il y a deux tribunaux supérieurs qui se divisent la tâche de juger les recours qui ne sont pas considérés ordinaires. Le Supérieur Tribunal de Justice (STJ), avec 33 ministres, juge les recours spéciaux (dénommés Recurso Especial) quand il y a violation de la loi fédérale ou divergence jurisprudentielle entre les tribunaux locaux dans des questions infra-constitutionnelles. Au contraire, quand il y a violation, par une décision judiciaire, des dispositions constitutionnelles le recours est extraordinaire (Recurso Extraordinário), jugé par le Tribunal Suprême Fédéral (STF). (p. 124)

\section{Procedimentos de Equivalência}

A equivalência consiste em substituir um vocábulo ou expressão da língua original por outro(s) na língua da tradução que lhe seja(m) funcionalmente equivalente(s).

Optar pela equivalência funcional na tradução jurídica "significa aceitar que a tradução seja uma atividade que pode ser qualificada de analógica no sentido de que não é uma ciência que comporta termos precisos e unívocos mas, antes, termos aproximados, a rigor equivalentes, e quase sempre desiguais" (Gonzalez, 2003, p. 50).

\section{a) Equivalência (seguida de Estrangeirismo)}

- Pour remédier à cet état de choses, le roi Don José I, en 1753, ordonna à un magistrat (desembargador), Ignacio Barbosa Machado, de réunir en une collection toutes les lois, les règlements et les résolutions expédiés jusque là aux possessions portugaises d'outre-mer ; [...] (p. 52)

○ Un décret (Alvará) du 30 octobre 1793 valide cette coutume et proclame formellement la validité des conventions ainsi conclues, [...] (p. 53)

- Chaque conseiller, desembargador, à commencer par le rapporteur, est invité à formuler son opinion sur l'affaire et à dire en quel sens il se prononce. [...] (p. 124125)

○ Le Tribunal de Justiça [...] Dans un grand État comme São Paulo, [...] il se divise en trois chambres correctionnelles et en six chambres civiles qui comportent chacune quatre juges (desembargadores). (p. 124) 


\section{b) Equivalência (seguida de Estrangeirismo) + explicação}

- En revanche une manifestation de doctrine, importante au Brésil, est constituée par la publication de consultations (pareceres) qui sont données par des professeurs ou avocats illustres, soit par les membres du ministère public, (elles correspondent aux « conclusions » françaises, mais sont publiées indépendamment de l'arrêt au prononcé duquel elles ont contribué), soit encore para les conseillers juridiques (consultores) qui existent soit à la présidence de la République ou auprès des gouverneurs des États [...] (p. 140)

○ Le Tribunal Suprême Fédéral, dans son organisation actuelle, comporte deux chambres (turmas). (p. 129)

\section{c) Questões de Não-Equivalência}

○ (...) les débats qui ont lieu fréquemment au Congrès fédéral, évoquant les dissensions entre certains États et la politique particulière de tel gouverneur, montrent avec évidence que le fédéralisme brésilien n'est pas un vain mot, (p. 47) et qu'il faut se garder de confondre les États du Brésil avec nos départements français. (p. 46)

- (...) Le Tribunal Suprême Fédéral, juridiction qui existe dans la capitale fédérale, n'exerce en effet sur leurs décisions qu'un contrôle restreint et ne peut être regardé comme l'équivalent de notre Cour de cassation. (p.124)

○ Cette fonction d'assurer l'uniformité de la jurisprudence, qui appartient au Tribunal Suprême Fédéral au Brésil, est liée à l'existence, dans ce pays, d'un très important corps de droit fédéral. Elle rapproche le Tribunal Suprême Fédéral de Rio de notre Cour de cassation, et le distingue de la Cour suprême des États-Unis, sur laquelle, à tant d'égards, on a copié son institution et les règles mêmes de son organisation. (p. 131)

Observa-se aqui que nem todas as não-equivalências configuram-se propriamente como dificuldades de tradução, sobretudo quando podem ser descritas pelo comparatista que analisa as divergências e semelhanças entre países.

Um outro excerto interessante foge do âmbito de questões puramente terminológicas e compara procedimentos discursivos entre países, desvelando a ausência de equivalência de posições enunciativas:

- Les arrêts brésiliens, par leur présentation actuelle, ressemblent de la sorte aux décisions judiciaires anglaises ou américaines beaucoup plus qu'aux arrêts français, lesquels sont strictement anonymes, supposés toujours rendus à l'unanimité, 
et rédigés sur un mode extraordinairement concis et technique. Dans les arrêts brésiliens, comme dans les arrêts anglais, tout est différent : la personnalité de tel ou tel juge s'affirme [...] Les Brésiliens sont satisfaits de leur système, qui fait ressortir la personnalité de leurs juges et donne à leurs décisions, il leur semble, plus d'autorité que l'anonymat des arrêts français (p. 125-126)

Convém salientar que essa divergência de posição enunciativa entre juízes brasileiros e franceses, descrita sem maiores problemas tradutórios por René David no âmbito do Direito Comparado, revela-se muito espinhosa para tradutores jurídicos e juramentados que traduzem constantemente o discurso decisório nas duas direções, língua materna-língua estrangeira e vice-versa. Há enormes discrepâncias nas posições enunciativas inflacionadas em primeira pessoa (discurso jurídico brasileiro) ou em terceira pessoa (discurso jurídico francês) e seus corolários pronominais, adjetivais e adverbiais, que evidentemente não respondem por nenhuma neutralidade, antes, enraízam-se fortemente em tradições jurídico-discursivas diversas.

Essas posições enunciativas literalmente traduzidas são o pano de fundo constante nas traduções juramentadas para o francês, por exemplo, de decisões judiciais brasileiras onde se traduz o mais literalmente um juiz falando em francês tão pleno de si mesmo e legislando o mundo em primeira pessoa... Tal paradoxo para a comunidade jurídica francófona receptora dessas traduções pode causar como efeito uma espécie de desconforto, reforçando ainda mais o sentimento de hibridez que resulta da apreensão da incongruência e da dessemelhança não apenas entre sistemas jurídicos, mas de posições enunciativas e discursivas enraizadas nas tradições dos juristas dessas distintas comunidades.

Um outro fator de estranhamento que chama a atenção de René David no curso aqui analisado é a densa presença no discurso jurídico brasileiro de um enorme aparelho citacional, que o comparatista imputa à grande influência de Ruy Barbosa: "O que impressiona, de fato, quando se lê uma obra, um parecer, uma sentença brasileira é a importância da doutrina, a frequência das citações de autores nacionais ou estrangeiros, o cuidado com o qual suas múltiplas opiniões são analisadas, confrontadas, criticadas" (p. 132).

Se tais citações não constituem fontes particulares de dificuldades para a tradução, a apresentação do direito brasileiro a franceses, em seu curso de doutorado dos anos 50, suscitou certamente a René David a necessidade de procedimentos tradutórios que se 
inscrevem como processo e produto do campo do Direito Comparado, fazendo escola e sendo bastante reveladores de uma certa concepção sobre o que seja comparar e traduzir.

Em duas obras, ele faz comentários sobre a imensa dificuldade de lidar com a diferença que cunha este campo. Em sua obra, Traité élémentaire de droit civil comparé, René David (1950, p. 283-284) enfatiza

\begin{abstract}
[...] Os conceitos elementares do direito francês, enfim, parecem muitas vezes ou bem não existir ou bem só ter no direito inglês uma importância de segunda ordem, a tal ponto que é, em geral, impossível traduzir na língua jurídica inglesa tal ou qual palavra que nos parece, a nós juristas franceses, exprimir um conceito jurídico fundamental; [...]

Inversamente, se considerarmos os livros de referência básica para os juristas ingleses, ao ler seus títulos, com frequência não compreenderemos do que se trata, e quando compreendermos, não encontraremos nenhuma palavra francesa para traduzir o conceito inglês, seja porque este é estranho ao direito francês, seja porque a língua francesa não possui, por conseguinte, nenhum termo satisfatório para traduzir em francês as palavras da língua jurídica inglesa, ou, contrariamente, para traduzir em inglês os termos usados pelos juristas franceses.

Essa diferença dos conceitos, aos quais recorrem os juristas dos dois países, é muito fundamental, e é ela, mais do que qualquer outra diferença na teoria geral das fontes do direito que faz da common law um grupo jurídico à parte, inteiramente distinta do grupo do direito francês. Com efeito, ela tem uma consequência do mais amplo alcance. Dela resulta que o jurista francês que se sentia à vontade no direito italiano, no direito uruguaio e no direito alemão se encontra completamente desorientado quando entra em contato com o direito inglês. Ali tudo o que aprendeu se torna inútil: é preciso que reaprenda a pensar, a falar e a ler, a compreender o sentido de cada uma dessas palavras e de cada uma dessas novas noções, que ele não conhecia no estudo de seu próprio direito.
\end{abstract}

Numa outra obra, Os grandes sistemas do Direito Contemporâneo, ele discorre assim sobre a questão das dessemelhanças entre famílias do direito e suas consequências para a tradução:

[...] o direito inglês vai mostrar-se muito diferente do direito francês e dos outros direitos da família romano-germânica. A sua estrutura não é a mesma que a do nosso direito e nessa diferença reside a maior dificuldade que nos oferece o estudo do direito inglês. A diferença de estrutura que iremos observar é efetivamente total. [...] Não correspondendo a nenhuma noção do nosso conhecimento, os termos do direito inglês são intraduzíveis nas nossas línguas, como o são os termos da fauna ou da flora de um outro país. Falseia-se o seu sentido, na maioria das vezes, quando se pretende a todo custo traduzi-los, e a dificuldade não é menor quando a tradução parece não oferecer dúvidas: o contrat do direito francês não é o equivalente do contract do direito inglês, tal como a equity inglesa não é a équité francesa; [...] (David, 1964, p. 382).

É pertinente ressaltar aqui o limiar extremamente tênue entre a teoria da tradução jurídica do grande comparatista francês e suas possibilidades efetivas de aplicação. Como ressalta outro eminente jurista, Rodolfo Sacco, em sua obra Introdução ao direito comparado 
(1980/2001), sempre inúmeros são os problemas da tradução jurídica. A título de exemplo, ele cita o UNIDROIT, Instituto internacional para a unificação do direito privado, que, em 1974, preparava um código internacional. O anteprojeto dos primeiros capítulos, bilíngue em francês e inglês, fora confiado a três grandes comparatistas: o próprio R. David, T. Popescu e C. Schmitthoff. Sacco constata que o art. $2^{\circ}$ do anteprojeto tratava de contract e de contrat, termos que sabidamente por todos, e mais ainda por René David, não se recobrem... Segundo o comparatista italiano,

A formulação do anteprojeto apresentava aos seus autores problemas que não podiam ser resolvidos no plano da tradução. [...] Neste caso, porém, o texto deveria esclarecer quais elementos devem acrescentar-se ao acordo para que este recaia nas hipóteses previstas no texto legal e vincule as partes. (p. 56)

Depreende-se facilmente que os próprios eruditos, importantes doutrinadores na área do Direito Comparado, podem igualmente sucumbir às armadilhas tradutórias com que se deparam. As impossibilidades da tradução jurídica são vultosas mesmo para grandes especialistas. Comparar e traduzir só acedem a ser chamados como tais na dessemelhança, naquilo que, em sua diferença, não se submete a outra língua-cultura, naquilo que de si não se alarga o bastante para se deixar dizer em toda sua evidência.

Ora, se na tradução jurídica, na melhor das hipóteses, como observado por JeanClaude Gémar (2002: 173), “da confrontação dos textos sairá um tertium quid, uma outra língua, um híbrido, em suma, que não é nem totalmente a cópia do original, nem verdadeiramente um texto conforme na letra nem no espírito ao sistema de chegada", esse efeito de hibridez, na comparação jurídica com efeitos tradutórios, é uma marca absolutamente inequívoca do gênero.

A tal ponto que a presença substantiva do outro, apresentado em sua estranheza e estrangeiridade, acaba se pondo paradoxalmente a serviço de uma certa domesticação, pois que parece responder à irresistível e inevitável finalidade de autorrepresentação que bem pode ser expressa na máxima Digo quem és para me fazer magnanimamente quem sou. Em outras palavras, o outro é indefectivelmente também o espelho a partir do qual aquele que compara (e traduz) cria imagens de si para se ler com todo garbo e pompa: erudito, cosmopolita, ilustrado, instruído, doutrinado, doutrinário, letrado, luminar e sábio... Portas bem abertas para a autofiguração que o permitem traduzir-se aqui sem absolutamente nenhum impasse ou constrangimento: "Espelho, espelho meu, existe alguém mais douto do que eu?" 
Referências bibliográficas:

BARBOSA, Heloísa. Procedimentos Técnicos da Tradução. São Paulo: Pontes, 1990.

DAVID, René. Traité élémentaire de droit civil comparé. Introduction à l'étude des droits étrangers et à la méthode comparative. Paris: R. Pichon et R. Durand-Auzias, 1950.

. Os grandes sistemas do Direito Contemporâneo. Tradução Hermínio A. Carvalho. São Paulo: Martins Fontes, 2002 [edição francesa 1964].

GEMAR, Jean-Claude. Le plus et le moins-disant culturel du texte juridique. Langue, Culture et équivalence. Meta, vol 47, no 2, junho 2002, p. 163-176.

GONZALEZ, Gladys. L'équivalence en traduction juridique : Analyse des traductions au sein de l'Accord de libre-échange Nord-Américain (ALENA). Québec, 2003. 419p. Thèse de Doctorat. Département de langues, linguistique et Traduction, Université de Laval.

MONJEAN-DECAUDIN, Sylvie. La traduction du droit dans la procédure judiciaire. Contribution à l'étude de la linguistique juridique. Paris : Dalloz, 2012.

PICARD, Etienne. L'état du droit comparé en France en 1999. Revue international de droit comparé. 1999, vol. 51, nº 4, p. 885-915.

SACCO, Rodolfo. Introdução ao Direito Comparado. Tradução Véra Jacob de Fradera. São Paulo: Editora Revista dos Tribunais, 2001 [edição italiana 1980].

WALD, Arnoldo e JAUFFRET-SPINOSI, Camille. (sous la dir.). Le droit brésilien : hier, aujourd'hui et demain. Paris : Société de Législation Comparée, 2005. 